\title{
What is "sufficient" complexity when modelling urine patches in grazed pastures?
}

\author{
$\underline{\text { V.O. Snow }}^{\text {a }}$, R. Cichota a, R.J. McAuliffe ${ }^{\text {a }}$, R.A. Dynes ${ }^{\text {a }}$, I. Vogeler ${ }^{\text {b }}$, S.F. Ledgard ${ }^{\text {b }}$, M.A. Shepherd ${ }^{\text {b }}$ \\ ${ }^{a}$ AgResearch - Private Bag 4749, Christchurch 8140, New Zealand \\ ${ }^{b}$ AgResearch - Private Bag 3123, Hamilton, New Zealand \\ Email: Val.Snow@agresearch.co.nz
}

\begin{abstract}
It is well-known that urine patches are the primary source of $\mathrm{N}$ leaching from intensively grazed pastures. Grazing ruminants regularly harvest $\mathrm{N}$ in pasture from the whole paddock but then deposit the majority of that ingested $\mathrm{N}$ into small areas or patches with high $\mathrm{N}$ loadings - perhaps of 200 to $2000 \mathrm{~kg} \mathrm{~N} / \mathrm{ha}$ covering only 2 to $5 \%$ of the paddock area. Such loadings are far in excess of the ability of plants to use the $\mathrm{N}$ within a growing season and this is the major driver of leaching in grazed systems. Despite this knowledge, most simulation models ignore the patch nature of urine $\mathrm{N}$ returns to pastures and assume a uniform paddockwide application of urinary $\mathrm{N}$ - primarily because of the increased simulation runtime that a patchy return would bring to models. New technology in the simulation model APSIM now allows routine simulation of within-paddock heterogeneity of soil carbon and nitrogen and this can be used to represent individual urine patches. This new technology also opens up questions as to what degree of complexity is necessary. Here we use some new data of individual urine patch load and wetted area that was measured from six dairy herds with a variety of physiological states for six hours a day over seven days (Figure 1). The data shows very high variability and we combined it with the new technology to understand if the complexity of individual urine patch characteristics should be used, or if it is sufficient to include urine patches with average size and load.
\end{abstract}

Simulations were set up in contrasting environments for $\sim 1200$ individual urine patches deposited over a 24hour period in either March or September and various outputs, but primarily leaching, examined for 24 months after deposition. Simulations with the full complexity of individually varying load and varying area (VL-VA), as shown below, were contrasted with equivalent simulations using the fixed average load and area (FL-FA).

Although the VL-VA simulations had soil mineral amounts that were highly spatially variable, the flow-on effect to whole-paddock pasture production and leaching were minimal. Using this data set alone (Figure 1) we would conclude that consideration of individual patch characteristics is not necessary but with the caveats that we have not yet considered whether this finding holds for the sequential or repeated grazing and deposition events. Also, given that the data shown in Figure 1 are not generally available, it would be prudent to repeat the analysis to investigate if correlation between urine patch load and area might change this conclusion.

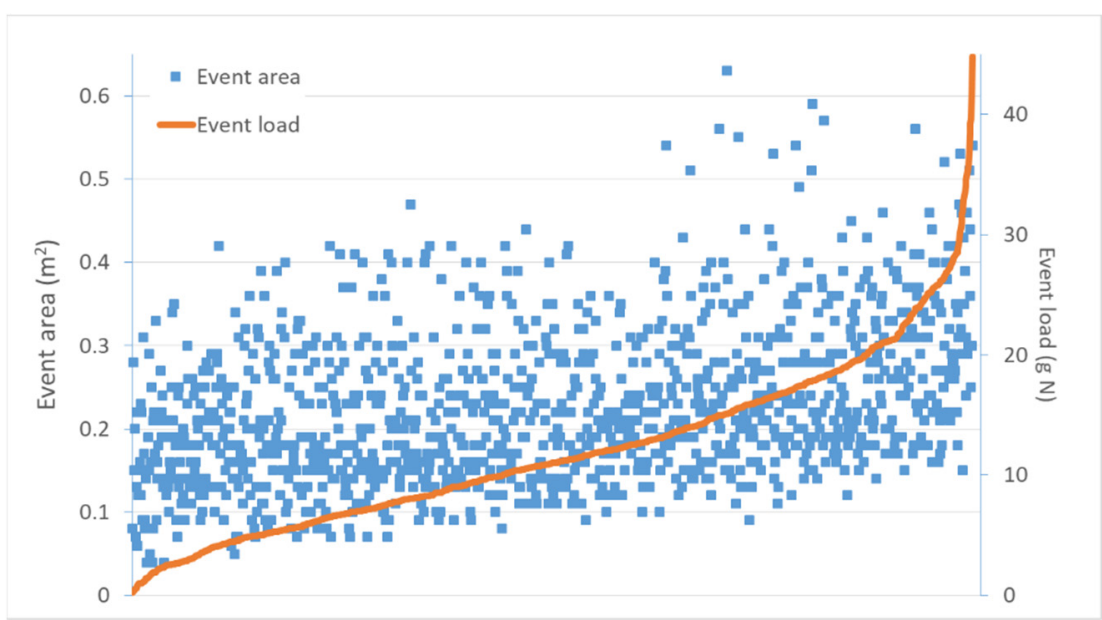

Figure 1. Individual urine patch area (blue symbols, left axis) and $\mathrm{N}$ load (orange line, right axis) from the experimental measurements showing the data sorted in order of increasing event load.

Keywords: $\quad$ Pastoral farming systems, APSIM, process-based modelling, leaching 
Snow et al., What is "sufficient" complexity when modelling urine patches in grazed pastures?

\section{INTRODUCTION}

Grazing ruminants are the core of pastoral farming enterprises but their excretion behaviour can lead to large losses of nitrogen $(\mathrm{N})$ via leaching because urine patches have loadings of $\mathrm{N}$ far in excess of the ability of the plants to take up and use before a significant drainage event occurs. Selbie et al. (2015) found literature giving ranges of patch-level $\mathrm{N}$ loading varying between 200 and $2000 \mathrm{~kg} \mathrm{~N} / \mathrm{ha}$ and typically the area affected by urine patches at a single intensive grazing event might be 2 to $4 \%$ of the paddock area.

Both experimental and modelling studies (e.g. Hutchings et al., 2007; Snow et al., 2009) have shown that these urine patches drive the $\mathrm{N}$ leaching from grazed pastures. Despite this, most simulation models assume a uniform return of excreted $\mathrm{N}$ to the soil surface - most likely because of the additional complexity of the simulations with patchy return and because of significantly increased run time. Recently Snow et al. (2017) demonstrated a simplified approach to modelling patchy $\mathrm{N}$ returns to the soil but some unknowns remained. Included in these was how to deal with the high event-to-event variability in the area and load in each urine patch. Experimental work has shown high variability in the concentration of $\mathrm{N}$ in excreted urine (e.g. Hoogendoorn et al., 2010; Shepherd et al., 2017) and while the variability in the size of urine patches was known, it was not well quantified. Also unknown was the possible relationship between the size and load in urine patches.

In a recent experiment Ledgard et al. (2017) identified individual urine patches during grazing events, marked the area wetted by the urine, and measured the $\mathrm{N}$ load in those patches. The aim of the study reported here was to use the gridded-paddock simulation approach developed by Snow et al. (2017) to understand if the simplifying assumption of an average urine $\mathrm{N}$ load and patch area was justifiable or if the all aspects of the variability in urinary $\mathrm{N}$ deposition should be included in the simulation.

\section{METHODS}

\subsection{Urine patch characteristics}

Ledgard et al. (2017) visually identified and sampled individual urine patches from six milking or dry dairy herds with a variety of physiological states for six hours a day over seven days. The wetted area of each urine patch was measured and sampled to obtain the amount of $\mathrm{N}$ excreted in each event. The amount of $\mathrm{N}$ in single urination events varied 224-fold from 0.2 to $44.8 \mathrm{~g} \mathrm{~N}$ (average $12.1 \mathrm{~g} \mathrm{~N}$, median $11.0 \mathrm{~g} \mathrm{~N}$ ) with skew in the data for few high-load events (Figure 1, orange line, see abstract). The wetted area in individual patches varied nine-fold between 0.07 and $0.63 \mathrm{~m}^{2}$ (average $0.23 \mathrm{~m}^{2}$, median $0.21 \mathrm{~m}^{2}$ ). When the area of soil wetted at each event was plotted with its $\mathrm{N}$ load (Figure 1) it is clear that, although there is substantial variation within both load and area, and that there is little relationship ( $\mathrm{r}^{2}$ of -0.28$)$ between these at an individual patch level.

Given the variability in load and area, the challenge is to understand if the variation is ignored (i.e. averaged) how will that affect the simulated $\mathrm{N}$ leached? We studied this by using the data shown in Figure 1 to generate individual urine patches in a paddock following a single simulated grazing event and examined the amount of simulated $\mathrm{N}$ leached in the 24 months following deposition. The simulation either included the variation in load and area shown in Figure 1 (variable load - variable area, VL-VA) or used an average or fixed load and area so that all patches were the same (fixed load - fixed area, FL-FA). Note that VL-FA and FL-VA combinations were also studied but have not been included in the results presented here. The total amount of $\mathrm{N}$ returned to the paddock was the same in both cases. The location of the urine patches was random, so allowing for overlapping patches.

\subsection{Gridded paddock setup}

The gridded paddock simulation method described in Snow et al. (2017) was used in these simulations and only a single grazing event was simulated so as to better understand the effects of choice of simulation design. A single 24-hour grazing event in a dairy farm might involve a stocking density of 100 cows /ha with 12 urinations /cow /day. Fortuitously there were 1198 urination events sampled by Ledgard et al. (2017) in which they were able to identify both load and area so all the sample data were used to represent a single grazing event. This avoided the need for any sampling of the distribution. Note that the data set of Ledgard et al. (2017) did not include any night-time data. While we cannot currently assess if this data gap has skewed the loads or areas of patches, here we are concerned about the effect of averaging rather than the area or load itself so the data gap is unlikely to compromise the results.

A grid size of $0.1 \mathrm{~m}^{2}(0.316 \mathrm{~m} \times 0.316 \mathrm{~m}, 100,000$ grid squares /ha) was selected for this study so that each urine event could be spread over several grid squares, creating a realistic representation of overlaps of patches. 
Ledgard et al. (2017) measured the wetted area of each urine patch but pasture outside the wetted area can access the urine $\mathrm{N}$ and effectively increase the size of the patch (Buckthought, 2013; Dennis, 2009). Here an edge effect length of $0.15 \mathrm{~m}$ was chosen. The effective area of each urine patch was obtained by: calculating the wetted radius assuming a circular geometry; adding $0.15 \mathrm{~m}$ to that radius; calculating the effective area; dividing that area by $0.1 \mathrm{~m}^{2}$ to give the number of grid squares for the patch; and finally rounding the result to the nearest $0.1 \mathrm{~m}^{2}$ so that only whole grid squares were used. The areal load $(\mathrm{kg} \mathrm{N} / \mathrm{ha}$ within a grid square) was calculated by dividing the urine $\mathrm{N}$ load by the area of grid squares used.

The location of each individual urine patch was selected by using a random number generated to provide an easting and northing, each between 1 and 316. This located the central grid square for each urine patch. An appropriate number of additional grid squares for each individual urine patch (according to the calculation described above) were selected by choosing the grid squares surrounding the central square following the sequence shown in Figure 2 on the left. In some cases the random selection resulted in parts of the urine patch falling outside the $316 \times 316$ grid in the modelled region. These were ignored. Once the grid squares for each urine patch were selected, the urine load was distributed evenly across those grid squares to provide a patcharea load in $\mathrm{kg} \mathrm{N} / \mathrm{ha}$. This scheme is represented in the centre of Figure 2 for one particular urine patch. The area was expanded from $0.56 \mathrm{~m}^{2}$ as measured (plus edge effect) to $0.6 \mathrm{~m}^{2}$ to accommodate for the grid size and the measured $\mathrm{N}$ load of $21 \mathrm{~g} \mathrm{~N}$ spread across the $0.6 \mathrm{~m}^{2}$ to give $350 \mathrm{~kg} \mathrm{~N} / \mathrm{ha}$ in the urine-affected grid squares.

In the VL-VA simulations the central location of each individual patch was randomly selected and then the individual area and load were applied for that patch. This resulted in a scattering of patches across the paddock with the areal $\mathrm{N}$ load (i.e. $\mathrm{kg} \mathrm{N} / \mathrm{ha}$ within the grid square) varying as measured in the individual urine patches but also because of overlaps resulting from the random placement. A $15 \mathrm{~m}$ by $15 \mathrm{~m}$ section of the paddock is shown in Figure 3 displaying an example of the $\mathrm{N}$ load distribution.

The VL-VA simulations included the full representation of the measured variability in load and area of individual urine patches. Equivalent fixed load - fixed area (FL-FA) simulations were run in which the average load and area of the urine patches was used for all patches. The load was slightly adjusted from the average to ensure that the total $\mathrm{N}$ applied to the paddock was the same in both simulations at $14.5 \mathrm{~kg} \mathrm{~N} / \mathrm{ha}$. The FL-FA urine patches were $0.5 \mathrm{~m}^{2}$ or 5 grid squares and had a modelled load of $242 \mathrm{~kg} \mathrm{~N} / \mathrm{ha}$ as depicted on the right in Figure 2. Although all FL-FA urine patches were equal, overlaps as the result of random placement were allowed.

The VL-VA and FL-FA simulations were run in two contrasting environmental conditions. Ruakura simulations were for the warm moist Waikato region in New Zealand using a soil with $137 \mathrm{~mm}$ of plantavailable water to $0.9 \mathrm{~m}$ deep and was not irrigated. Lincoln simulations were for the cooler drier Canterbury region using a soil with $88 \mathrm{~mm}$ of plant-available water to $0.9 \mathrm{~m}$ deep and centre-pivot irrigation was used. Full details of the simulation conditions can be found as systems B (Ruakura) and D (Lincoln) in Snow et al. (2017) excepting that no fertiliser was applied so as to accentuate differences between VL-VA and FL-FA. Urine depositions were simulated for March (autumn) and September (spring) for deposition years 1999 to 2013 inclusive. Each simulation was initialised three months before deposition (these data were discarded before analysis) and concluded two years after deposition.

\section{RESULTS AND DISCUSSION}

Figure 4 shows the variability in mineral $\mathrm{N}$ stored in the soil in three patches from one particular VL-VA simulation contrasted against the equivalent FL-FA simulation. Note that all these data are from within urine patches and do not represent whole-paddock amounts. Figure 5 shows the mineral $\mathrm{N}$ data from a sample of 60 of the 1198 urine patches. Two weeks after deposition, mineral-N varied between 0 and $841 \mathrm{~kg} \mathrm{~N} / \mathrm{ha}$ (median $175 \mathrm{~kg} \mathrm{~N} / \mathrm{ha}$ ) for the VL-VA simulations and 192 to $1013 \mathrm{~kg} \mathrm{~N} / \mathrm{ha}$ (median $207 \mathrm{~kg} \mathrm{~N} / \mathrm{ha}$ ) for the FL-FA simulations. Note that the total $\mathrm{N}$ deposited was the same in both simulation types at $14.5 \mathrm{~kg} \mathrm{~N} / \mathrm{ha}$. The variation in load for the FL-FA simulations was partially due to varying environmental and growth conditions but was primarily due to the positioning of the urine patches which allowed overlaps (as the positioning also did for VL-VA). The primary differences between the simulation types were the generally higher mineral-N in the FL-FA urine patches and the absence of urine patches with less than about $200 \mathrm{~kg} \mathrm{~N} / \mathrm{ha}$ in the FL-FA simulations. 
Snow et al., What is "sufficient" complexity when modelling urine patches in grazed pastures?

Variable load, variable area (VL-VA)

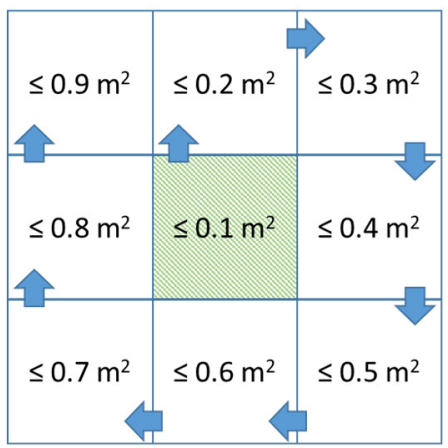

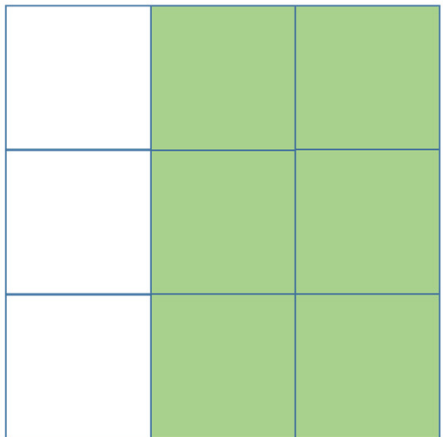

Event \#715:

- $0.56 \mathrm{~m}^{2} \rightarrow 0.6 \mathrm{~m}^{2}$

- $21.0 \mathrm{~g} \mathrm{~N}$

- $350 \mathrm{~kg} \mathrm{~N} / \mathrm{ha}$
Fixed load, fixed area (FL-FA)

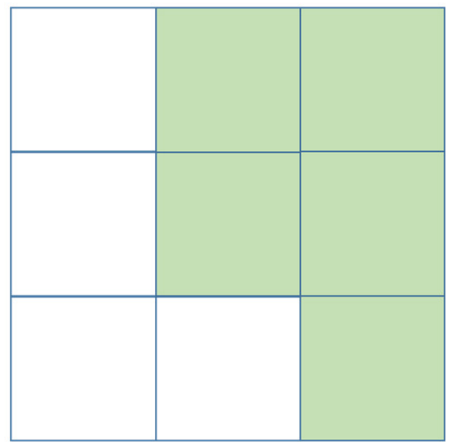

All events:

$0.54 \mathrm{~m}^{2} \rightarrow 0.5 \mathrm{~m}^{2}$

- $12.1 \mathrm{~g} \mathrm{~N}$

- $242 \mathrm{~kg} \mathrm{~N} / \mathrm{ha}$

Figure 2. Diagram showing the scheme of the grid squares in the simulation. The left diagram shows the shaded central square that is selected randomly. As more area is needed for the patch surrounding grid squares were selected as shown. The centre diagram shows one particular urine patch (as described in the text) from the VL-VA simulation with a modelled area of 6 grid squares or $0.6 \mathrm{~m}^{2}$ and a modelled $\mathrm{N}$ load of $350 \mathrm{~kg} \mathrm{~N} / \mathrm{ha}$. The right diagram shows a single patch (noting that all the patches were the same but in random locations) in the FL-FA simulation with a modelled area of $0.5 \mathrm{~m}^{2}$ and N load of $242 \mathrm{~kg} \mathrm{~N} / \mathrm{ha}$.

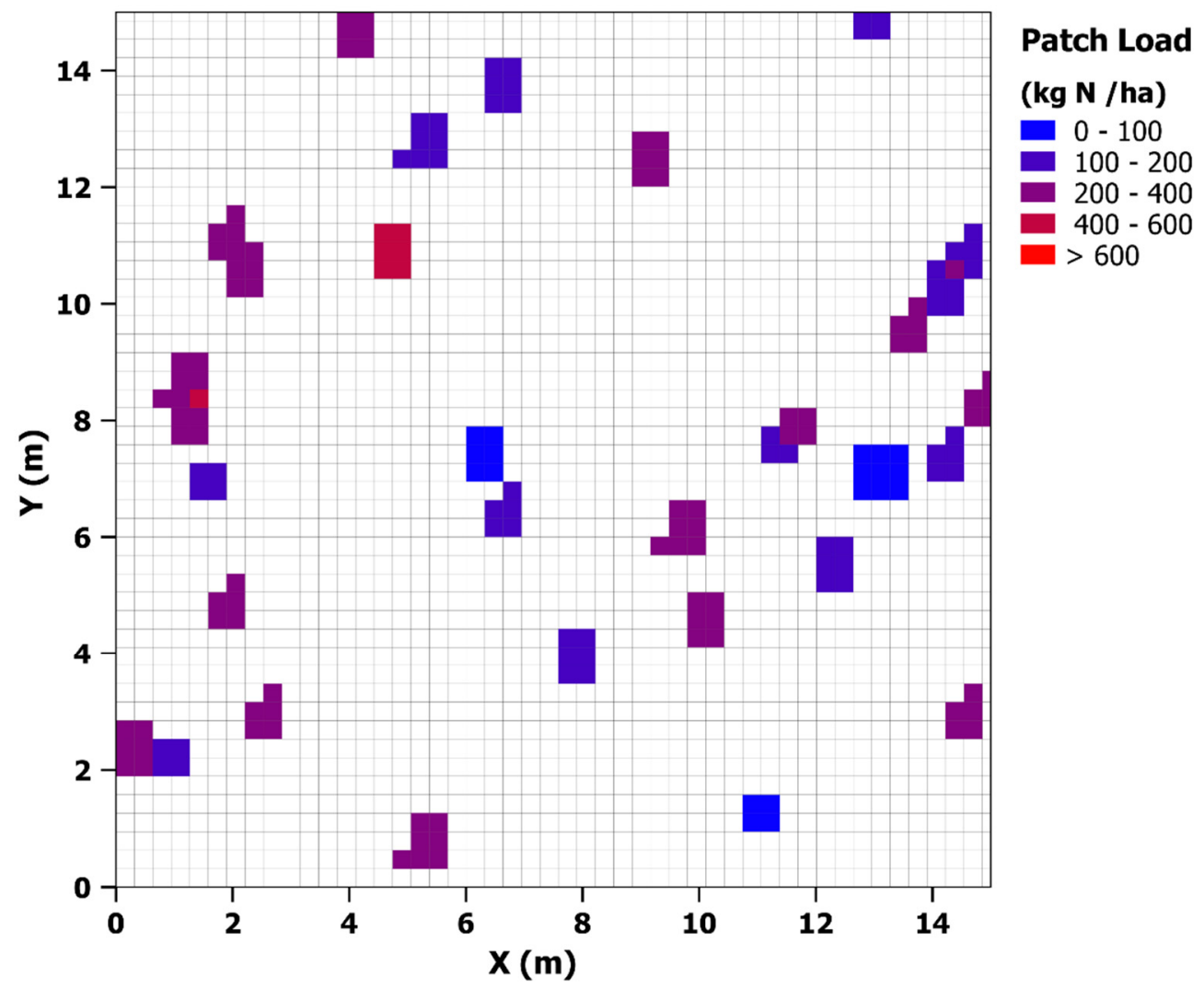

Figure 3. Diagram of part (15 m by $15 \mathrm{~m}$ ) of the modelled area for the variable-load variable-area (VLVA) simulation showing the placement, size and areal $\mathrm{N}$ loading (see colour scale) of the urine patches on the grid. The underlying grid shows the smallest unit modelled, $0.1 \mathrm{~m}^{2}$ (or $0.316 \mathrm{~m}$ by $0.316 \mathrm{~m}$ ). 
Snow et al., What is "sufficient" complexity when modelling urine patches in grazed pastures?

Despite these differences, simulation type had minimal effect on pasture growth rate. Figure 6 shows an example with the largest difference in growth rate. As uptake by pasture is the major fate of urinary-N, the minimal effects of simulation type on pasture growth flowed through to very small effects on $\mathrm{N}$ leaching from the different simulation types. Figure 7 compares $\mathrm{N}$ leached from the VL-VA simulations to the equivalent FL-FA simulation. There is almost no deviation from the 1:1 line showing that, for the assumptions here, it was not necessary to consider the variation in urine patch load or area in the simulation.

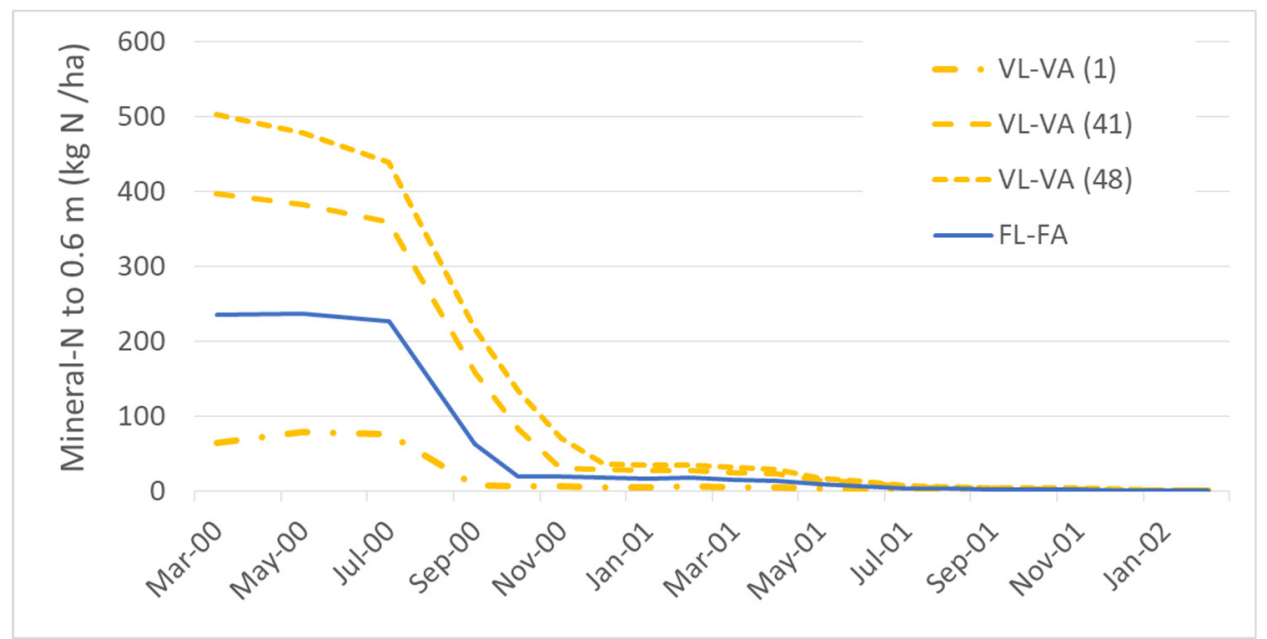

Figure 4. Three sample patches from the March 2000 VL-VA simulation in Ruakura showing varying mineral $\mathrm{N}$ in the soil contrasted with the equivalent FL-FA simulation.

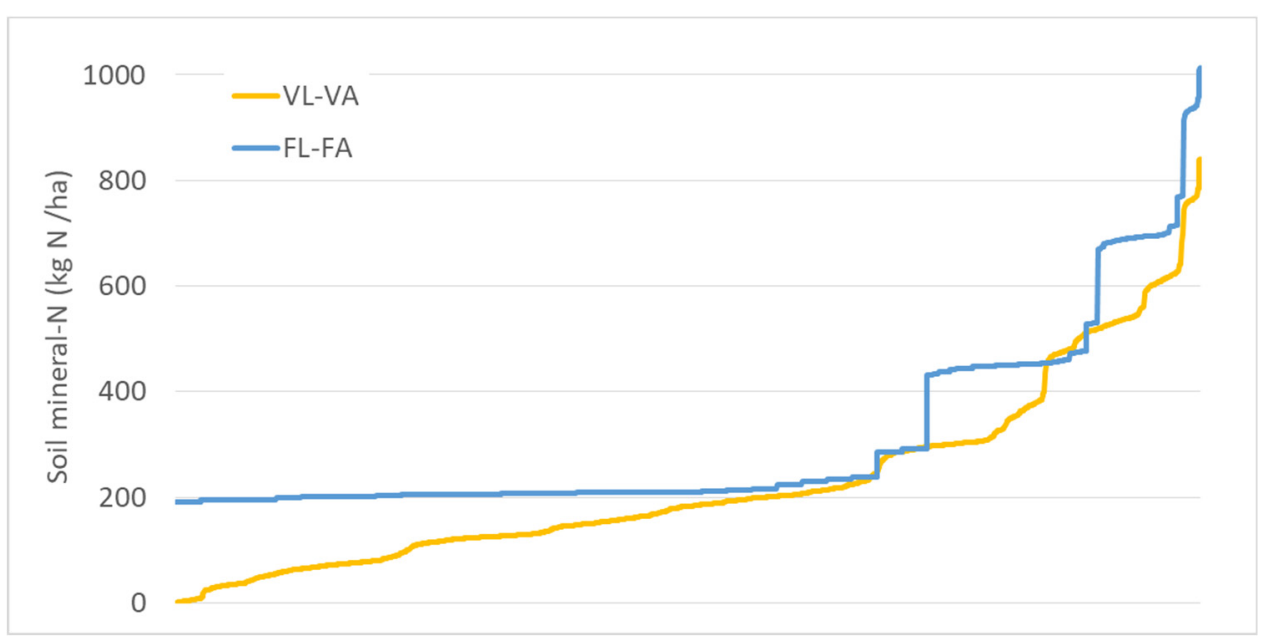

Figure 5. Simulated mineral-N two weeks after urine deposition from 60 sampled patches, amalgamated across all deposition years and months for the Ruakura simulations. The data are sorted in order of increasing mineral-N. 


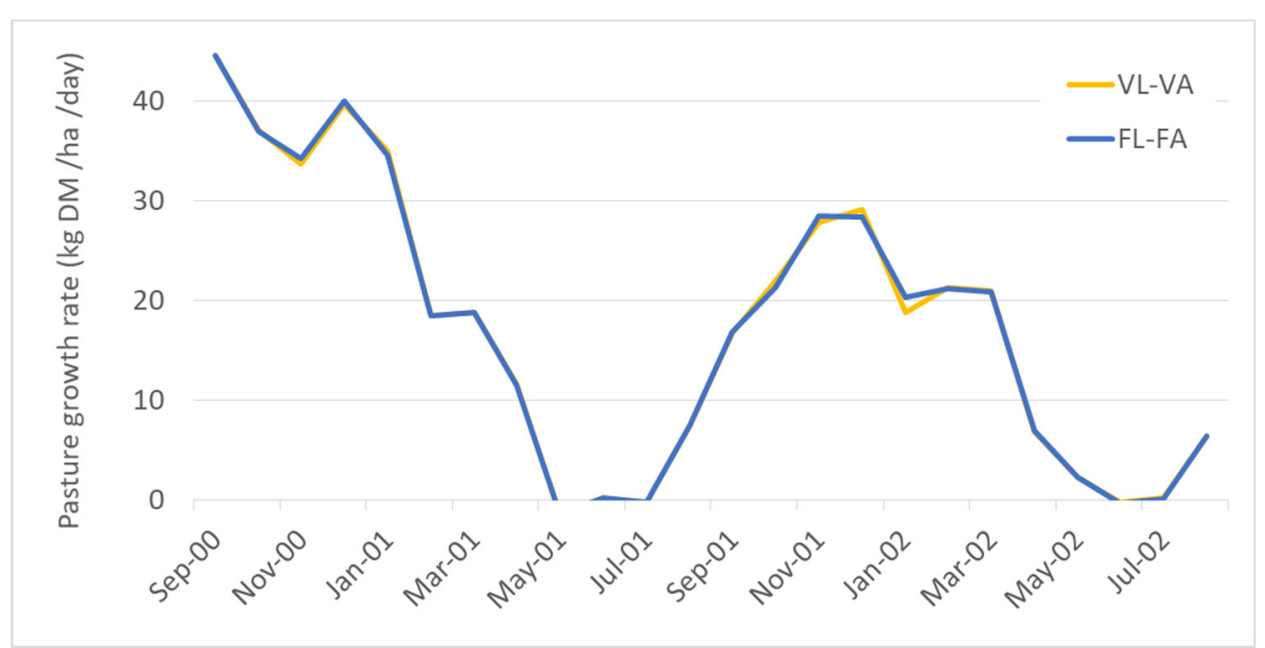

Figure 6. Pasture growth rate as simulated by VL-VA and FL-FA for the September 2000 simulation in Lincoln. Note that no fertiliser was applied to these simulations.

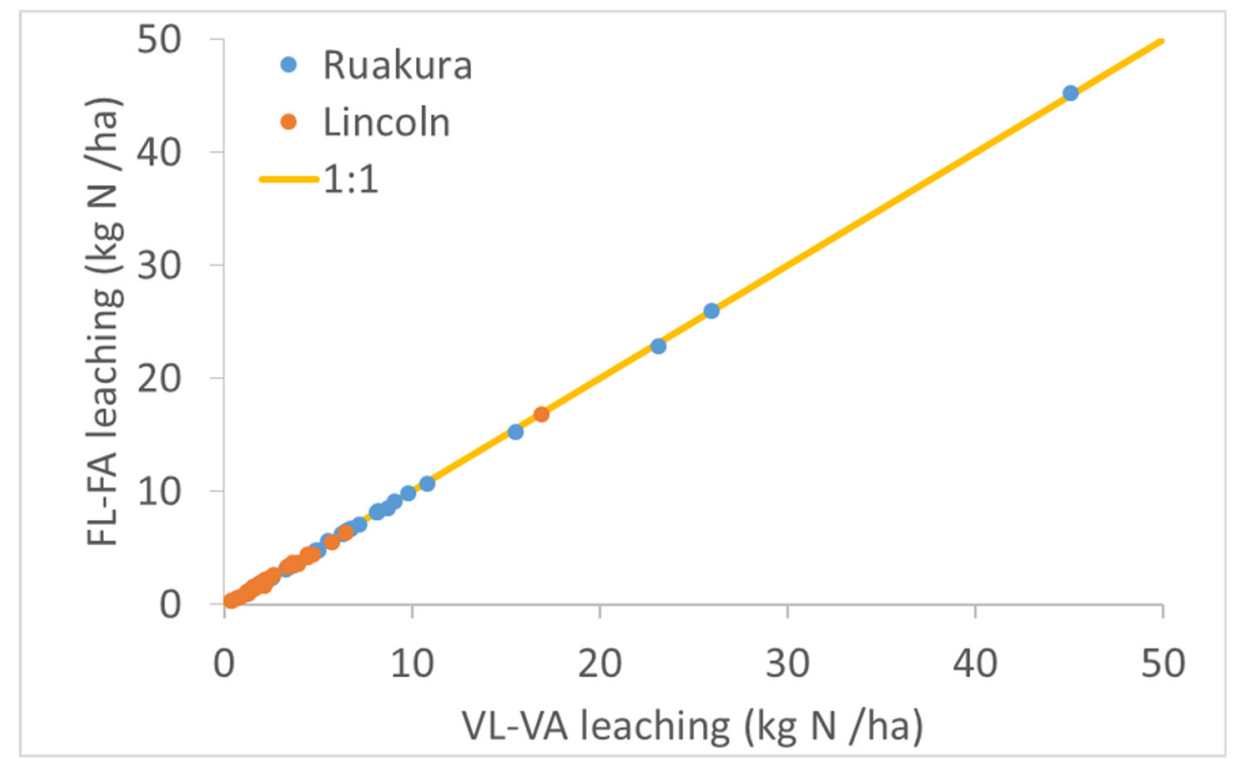

Figure 7. Leaching as calculated by the VL-VA simulation compared with the matching FL-FA simulation.

\section{DISCUSSION AND CONCLUSIONS}

There was very high variability in urine patch $\mathrm{N}$ load and area (Figure 1) measured by Ledgard et al. (2017). Using these in APSIM simulations, translated into high variability in mineral-N in the urine patches (Figure 5), but resulted in almost no differences in pasture growth rate (Figure 6) or N leaching (Figure 7). From the information presented here it seems that the representation of urine patches themselves is more important than the variation between urine patches. However these are initial conclusions and so should be interpreted with caution. In particular, the simulations here consider only a single deposition time in the simulation. Previous 
work (Cichota et al., 2013) has shown that urine patches that overlap in subsequent grazing events are more numerous and perhaps more important than those that overlap at a single grazing event. This effect was not included in this initial testing. In addition the data set of Ledgard et al. (2017) is the only one that we know of and did not include night-time urine depositions. Given this, additional testing with extended ranges and exploring the impacts when there is a possible correlation between urine patch load and area should be undertaken before more general conclusions are made.

\section{ACKNOWLEDGMENTS}

This research was completed as part of the Forages for Reduced Nitrate Leaching research programme with principal funding from the New Zealand Ministry of Business, Innovation and Employment (DNZ1301). The program is a partnership between DairyNZ, AgResearch, Plant \& Food Research, Lincoln University, the Foundation for Arable Research, and Landcare Research.

\section{REFERENCES}

Buckthought, L.E. (2013). The interactive effects of nitrogen fertiliser and animal urine on nitrogen efficiency and losses in New Zealand dairy farming. A thesis submitted in partial fulfilment of the requirements for the Degree of Doctor of Philosophy at Lincoln University. Lincoln University, New Zealand.

Cichota, R., Snow, V.O., Vogeler, I. (2013). Modelling nitrogen leaching from overlapping urine patches. Environmental Modelling \& Software, 41, 15-26. doi:10.1016/J.ENVSOFT.2012.10.011

Dennis, S.J. (2009). Nitrate leaching and nitrous oxide emission from grazed grassland: upscaling from lysimeters to farm. A thesis submitted in partial fulfilment of the requirements for the Degree of Doctor of Philosophy at Lincoln University. Lincoln University, New Zealand.

Hoogendoorn, C.J., Betteridge, K., Costall, D.A., Ledgard, S.F. (2010). Nitrogen concentration in the urine of cattle, sheep and deer grazing a common ryegrass/cocksfoot/white clover pasture. New Zealand Journal of Agricultural Research, 53, 235-243. doi:10.1080/00288233.2010.499899

Hutchings, N.J., Olesen, J.E., Petersen, B.M., Berntsen, J. (2007). Modelling spatial heterogeneity in grazed grassland and its effects on nitrogen cycling and greenhouse gas emissions. Agriculture Ecosystems and Environment, 121, 153-163. doi:10.1016/j.agee.2006.12.009

Ledgard, S.F., Macdonald, K.A., Roche, J.R. (2017). Effects of cow stocking rate and lactation on urination frequency and urinary-N spread. Report for the P21 II Investor Steering Group. Client Report Number: RE500/2017/008.

Selbie, D.R., Buckthought, L.E., Shepherd, M.A. (2015). The challenge of the urine patch for managing nitrogen in grazed pasture systems. Advances in Agronomy, 129, $229-292$. doi:10.1016/bs.agron.2014.09.004

Shepherd, M., Shorten, P., Costall, D., Macdonald, K.A. (2017). Evaluation of urine excretion from dairy cows under two farm systems using urine sensors. Agriculture Ecosystems and Environment, 236, $285-294$. doi:10.1016/j.agee.2016.12.017

Snow, V.O., Cichota, R., McAuliffe, R.J., Hutchings, N.J., Vejlin, J. (2017). Increasing the spatial scale of process-based agricultural systems models by representing heterogeneity: The case of urine patches in grazed pastures. Environmental Modelling \& Software, 90, 89-106. doi:10.1016/j.envsoft.2017.01.005

Snow, V.O., Johnson, I.R., Parsons, A.J. (2009). The single heterogeneous paddock approach to modelling the effects of urine patches on production and leaching in grazed pastures. Crop and Pasture Science, 60, 691696. doi:10.1071/CP08390 